\title{
A new Brazilian species of Isotomiella (Collembola: Isotomidae) from the state of Pará, Brazil
}

\author{
Maria Cleide de Mendonça ${ }^{1, *}$ \& Gabriel Costa Queiroz ${ }^{1}$
}

\author{
'Departamento de Entomologia, Museu Nacional, Universidade Federal do Rio de Janeiro. Quinta da Boa Vista, \\ São Cristóvão, 20940-040 Rio de Janeiro, RJ, Brazil. \\ *Corresponding author. E-mail: cleidecollembola@gmail.com
}

\begin{abstract}
A new species of Isotomiella from Pará State is described and illustrated. This new species belongs to the digitata group, but differs from other by the number of chaetae on manubrium and dens, teeth on the tenaculum and size of the sensilla on abdominal tergites $\mathrm{V}$-VI.
\end{abstract}

KEY WORDS. Biodiversity, digitata group, taxonomy.

The Brazilian fauna of Isotomiella Bagnall, 1939 comprises 22 species (ABRANTES et al. 2012), of which 12 were described for the Northern region (Deharveng \& Oliveira 1990, Oliveira \& Deharveng 1990) and 8 for the Southeastern region (Mendonça \& Fernandes 2003a, 2003b, MENdonÇA \& ABRANTEs 2007, MendonçA et al. 2012). In other regions of Brazil such as the Central-Western, records about this genus are unknown. Recent samples collected by the second author in the Municipality of Santarém (State of Pará) revealed the new species, Isotomiella louisi sp. nov., in the digitata group, which is defined here by the presence of a strongly thickened metathoracic tibiotarsus with several digitiform chaetae, and basal chaeta of the outer lobe of maxilla ciliated. The new species differs from other of the digitata group by the number of chaetae on manubrium and dens, the number of teeth on the tenaculum and the size of the sensillae, sa, spe, spi, on abdominal tergites V-VI.

\section{MATERIAL AND METHODS}

The material studied was obtained in September 2014, from soil samples collected near Tapajós River, in the municipality of Santarém, state of Pará. The fauna was extracted using Berlese Tullgren funnels, sorted under the stereomicroscope, and mounted on slides according to usual methodology. Illustrations and measurements were made using an ocular micrometer on an optic microscope. The type material is deposited in the Collembola Collection at Departamento de Entomologia, Museu Nacional/UFRJ, Rio de Janeiro, Brazil, under the acronym CM/ MNRJ. Abbreviations used in the description: (Abd) abdominal, (Ant) antennal, (Sa) anterior sensillum, (Spe) posterior external sensillum, (Spi) posterior internal sensillum, (Spl) dorso-lateral sensillum, (Sv) ventral sensillum, (Th) thorax, (Tita) tibiotarsi.

\section{TAXONOMY}

Isotomiella louisi sp. nov.

Figs 1-11

urn:lsid:zoobank.org:act:24177D3F-AEA9-4444-8A27-46BF4AF23989

Body length of holotype $0.71 \mathrm{~mm}$. Habitus slender and cylindrical, typical of the genus. Color white. Body chaetotaxy ciliated; few chaetae slightly ciliated or smooth. Integument without craters. Pseudopores and channels not visible.

Head. All chaetae ciliated and subequal, anterior and posterior chaetae longer (Fig. 1). Ant I (25 $\mu \mathrm{m})$ with 15 ciliated chaetae, 2 basal microchaetae, one dorsal and one ventral; 2 ventral unequal sensilla, one plump $(5 \mu \mathrm{m})$ and one $(3 \mu \mathrm{m})$ very thin. Ant II $(30 \mu \mathrm{m})$ with 26 ciliated chaetae and one dorso-basal microchaeta (Figs. 2, 3). Ant III and Ant. IV damaged. Labrum with 4 anterior spinules; labral chaetae pattern 4/5,5,4. Maxillary outer lobe bifurcated with basal ciliated chaeta and 3 sublobal hairs. Linea ventralis of head with $3+3$ chaetae.

Tergites. Th II with $9+9$ axial chaetae, $3+3$ lateral sensilla (5 $\mu \mathrm{m}, 7 \mu \mathrm{m}, 5 \mu \mathrm{m}), 1+1$ lateral macrochaetae $(45 \mu \mathrm{m})$ (Fig. 4). Th III with $6+6$ axial chaetae, $2+2$ lateral sensilla $(5 \mu \mathrm{m}), 1+1$ lateral macrochaetae $(55 \mu \mathrm{m})$ (Fig. 5). Abd I with $3+3$ axial chaetae, $1+1$ lateral sensilla, $1+1$ lateral macrochaetae $(56 \mu \mathrm{m})$. Abd II with $3+3$ axial chaetae, $1+1$ lateral sensilla $(4 \mu \mathrm{m}), 3+3$ macrochaetae $(60$ $\mu \mathrm{m})$ Abd III without defined pattern of axial chaetae, $1+1$ ventral sensilla $(4 \mu \mathrm{m})$ and $1+1$ lateral sensilla $(7 \mu \mathrm{m}), 3+3$ macrochaetae $(62 \mu \mathrm{m})$. Abd IV without defined pattern of axial chaetae, $1+1$ lateral sensilla, $3+3$ anterior macrochaetae $(62 \mu \mathrm{m})$ and $2+2$ posterior macrochaetae $(62 \mu \mathrm{m})$. Abd V-VI with several macrochaetae (65 $\mu \mathrm{m})$ among mesochaetae of different sizes (20-45 $\mu \mathrm{m}), 1+1 \mathrm{spl}$ 


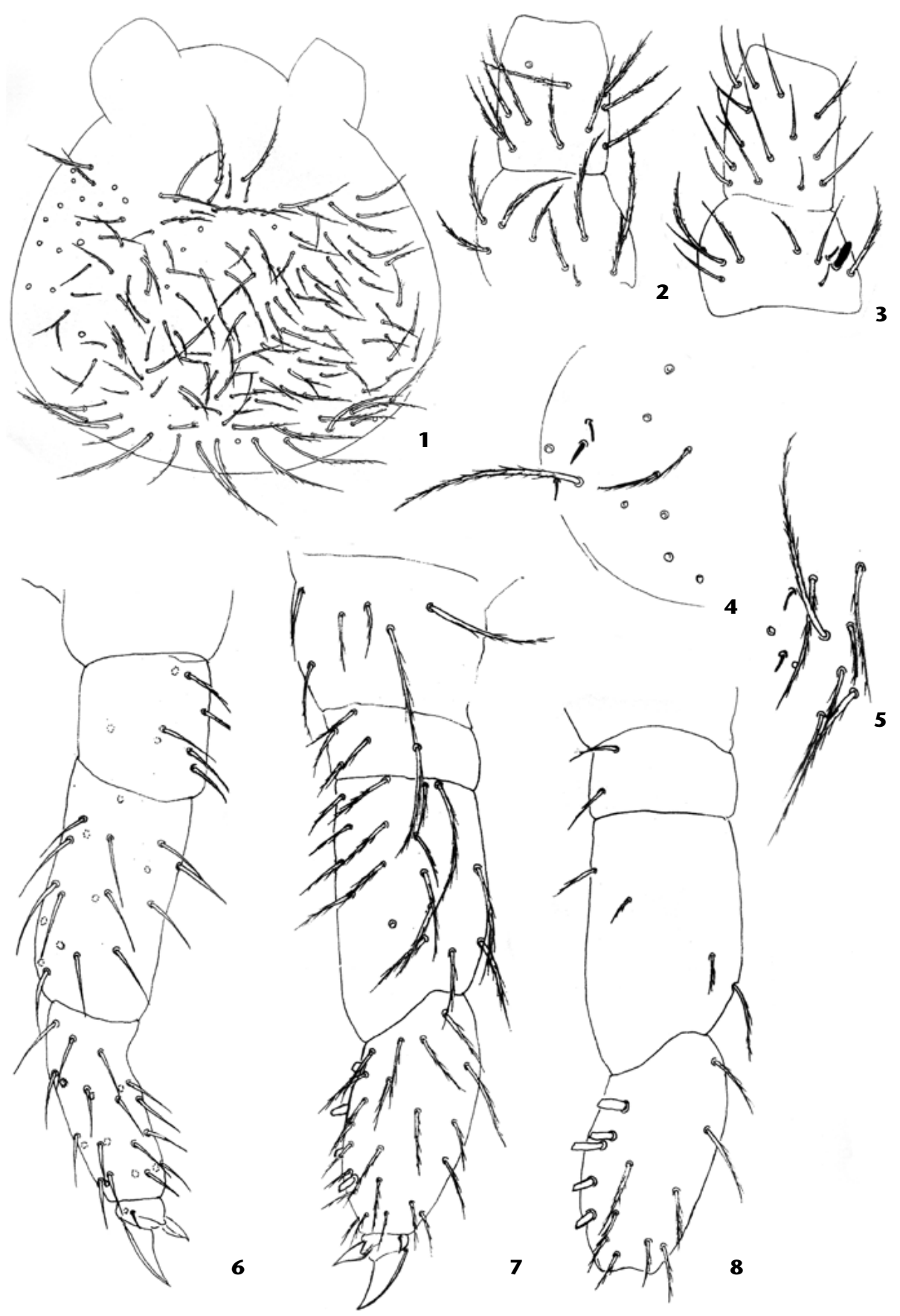

Figures 1-8. Isotomiella louisi sp. nov.: (1) dorsal chaetotaxy of head; (2) antennal I-II, dorsal view; (3) antennal I-II, ventral view; (4) lateral sensillar pattern of Th II; (5) lateral sensillar pattern of Th. III; (6) leg III, external view; (7) leg III, internal view; (8) leg I, external view.

long, thick and slightly curved dorso-lateral sensilla $(35 \mu \mathrm{m}), 1+1$ ventral sensilla sv with $(4 \mu \mathrm{m})$ and $3+3$ dorso-lateral sensilla sa, spe, spi very long and thin each with $38 \mu \mathrm{m}, 45 \mu \mathrm{m}$ and $40 \mu \mathrm{m}$ respectively (Fig. 11). Sensillary formula by half tergite 3,2/1,1,2,1,5. Unpaired chaetae a0, m0, p0 not visualized.
Appendages. Subcoxa III with about six ciliated chatae, longer; Femur III with about 19 ciliated chaetae; Tita III strongly thickened, with about 31 ciliated chaetae and 5 digitiform chaetae (Figs. 6, 7). Femur I with about 19 ciliated chaetae; Tita I (Fig. 8) and II of normal shape, with 24-26 and 26-27 chaetae 


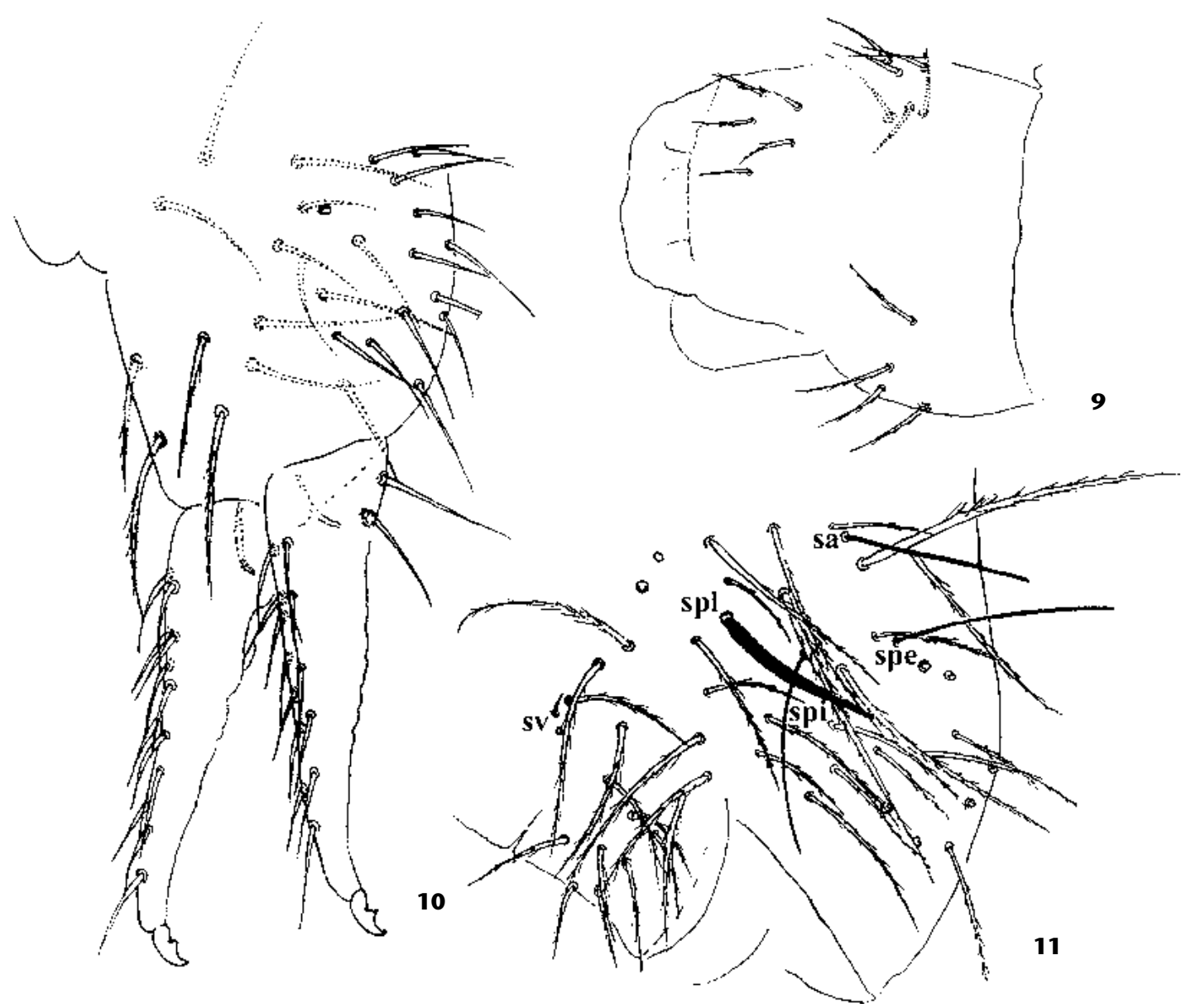

Figures 9-11. Isotomiella louisi sp. nov.: (9) ventral tube, ventro-lateral view; (10) furcula; (11) abdominal V-VI, lateral sensillar pattern.

respectively. Tita I, II and III with 7 chaetae on distal whorls; tibiotarsal tenent chaetae pointed. Unguis of normal shape (18 $\mu \mathrm{m})$, without teeth; unguiculus lanceolate $(8 \mu \mathrm{m})$. Ventral tube with $3+3$ anterior, $2+2$ posterior and $5+5$ distal chaetae (Fig. 9). Tenaculum $(20 \mu \mathrm{m})$ with $4+4$ teeth and one chaeta. Furcal anterior subcoxae with 6 chaetae, three of them longer. Furcal posterior subcoxae with 6 chaetae, one longer. Manubrium (40 $\mu \mathrm{m}$ ) with $2+2$ anterior, 20 posterior and no lateral chaetae. Dens slightly crenulated $(56 \mu \mathrm{m})$ with 13 anterior and 2 posterior chaetae. Mucro small, $(5 \mu \mathrm{m})$ bidentate (Fig. 10).

Material examined. Holotype female, Brazil, Pará: Santarém municipality (Alter do Chão, litter near Tapajós River margin, secondary Amazon Forest, local coordinates

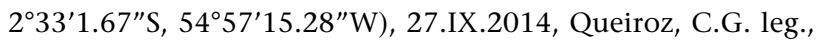
$2489 \mathrm{CM} / \mathrm{MNRJ}$.

Etymology. The species epithet is to honor Dr. Louis Deharveng for his great contribution to the knowledge of Isotomiella.

Remarks. The new species, Isotomiella louisi sp. nov., belongs to a group of species proposed here as the I. digitata group.
The group includes three Brazilian species (I. digitata Deharveng \& Oliveira, 1990, I. distincta Mendonça \& Fernandes, 2003 and $I$. falcata Mendonça \& Fernandes, 2003) that share two remarkable apomorphies: metathoracic tibiotarsus strongly thickened with several digitiform chaetae, and basal chaeta of maxillary outer lobe ciliated. The new species, I. louisi sp. nov. also shares with them the following characteristics: chaetae of body ciliated; unguis toothless; and reduced furcula with few chaetae $(1+1-2+2)$ on anterior side of manubrium. The species I. macedoi Mendonça et al. 2012 has tibiotarsus III of male similar to the condition found in $I$. digitata group, but differs from it by the presence of a set of characteristics: sensillary pattern $(3,2 / 0,0,1,3,5), 3+3$ to $5+5$ ventral chaetae of manubrium, mucro tridentate and 4 sublobal chaetae found in minor and nummulifer group sensu Kóvac \& Palacios-Vargas (2008). Furthermore, in I. macedoi the basal chaeta of the maxillary outer lobe is smooth, the digitiform chaetae are thinner on metathoracic tibiotarsus and are only present in the male. The digitata group can be separated from other groups of Isotomiella defined so far by the table in Kovác \& Palácios-Vargas (2008). 
Table 1. Comparison among species of digitata group.

\begin{tabular}{lllll}
\hline & l. digitata & I. distincta & I. falcata & I. louisi sp.nov. \\
\hline Body size $(\mathrm{mm})$ & $0.40-0.45$ & 0.43 & 0.70 & 0.71 \\
Labral chaetae & $?$ & $?$ & $?$ & $4 / 5,5,4$ \\
Sublobal hairs & 3 & $?$ & 3 & 3 \\
Tergal macrosensilla & $3,2 / 1,1,2,1,5$ & $?$ & $?$ & $3,2 / 1,1,2,1,5$ \\
Digitiform tibiotarsal chaetae & 4 & 2 & 5 & 5 \\
Ventral tube chaetae & $5+5$ distal & $3+3$ distal & $3+3$ distal & $5+5$ distal \\
& $3+3$ anterior & $1+1$ anterior & $1+1$ anterior & $3+3$ anterior \\
& $2+2$ posterior & $1+1$ posterior & $1+1$ posterior & $2+2$ posterior \\
Ratio length sensillum spl/claw & $1.4-1.5$ & $2.5-3$ & $2.5-3$ & 1.9 \\
Tenaculum teeth/chaetae & $3+3 / 1$ & $3+3 / 1$ & $3+3 / 1$ & $4+4 / 1$ \\
Manubrium anterior chaetae & $1+1$ & $1+1$ & $1+1$ & $2+2$ \\
Manubrium posterior chaetae & $6+6$ & $?$ & $?$ & $10+10$ \\
Dens anterior chaetae & 6 & 6 & 6 & 13 \\
Dens posterior chaetae & 1 & 1 & 1 & 2 \\
Type of mucro & bidentate & bidentate & falcate & bidentate \\
\hline
\end{tabular}

The new species is similar to I. digitata, both share the same sensillar formula $(3,2 / 1,1,2,1,5)$ and the same number of chaetae on ventral tube. However, I. louisi sp. nov. differs by having 5 digitiform chaetae on tibiotarsus III (versus 4), manubrium with $2+2$ anterior chaetae (versus $1+1$ ), dens with 13 anterior and 2 posterior chaetae (versus 6 and 1 ) and $4+4$ teeth on tenaculum (versus 3+3) (Table 1).

Isotomiella louisi sp. nov. can be readily distinguished from I. distincta by the presence, in this last species, of 2 digitiform chaetae on tibiotarsus III, number of chaetae on ventral tube $(3+3$ distal, $1+1$ anterior, $1+1$ posterior) and $3+3$ teeth on tenaculum. The new species also resembles $I$. falcata, especially in the presence of five digitiform chaetae on tibiotarsus III, but it can be easily separated from it by its bidentate versus falciform mucro. Isotomiella louisi sp. nov. also deviates from species of the digitata group by having on Abd V-VI the sensillae, sa, spe, spi very thin and long, about twice as long as lateral macrochaetae on Th II.

\section{ACKNOWLEDGMENTS}

We are thankful to Fundação de Amparo à Pesquisa do Estado do Rio de Janeiro (FAPERJ E-26/111.504/2013) for financial support, to CNPq for grant to Maria Cleide de Mendonça (process 307644/2015-4) and to CNPq for the second author's grant.

\section{LITERATURE CITED}

Abrantes Ea, Bellini Bc, Bernardo An, Fernandes Lh, Mendonça Mc, Oliveira Ep, Queiroz Gc, Sautter Kd, Silveira Tc, Zeppelini D (2012) Errata Corrigenda and update for the "Synthesis of Brazilian Collembola: an update to the species list." Abrantes et al. (2010), Zootaxa 2388: 1-22. Zootaxa 3168: 1-21.

Deharveng L, Oliveira E (1990) Isotomiella (Collembola: Isotomidae) d'Amazonie: les espèces du groupe delamarei. Annales de la Société Entomologique de France (NS) 26: 185-201.
Kovác L, Palacios-Vargas JG (2008) Redescription of Isotomiella alulu and I. delamarei (Collembola: Isotomidae) with notes on systemattics of the genus and new records from the Neotropics. Zootaxa 1825:1-17.

Mendonça MC, Fernandes LH (2003a) New species of Isotomiella Bagnall, 1939 and Records of new occurrences of Isotomiella nummulifer and I. quadriseta from Brazil (Collembola, Isotomidae). Boletim do Museu Nacional 502: 1-12.

Mendonça MC, Fernandes LH (2003b) Três novas espécies de Isotomiella Bagnall, 1939 do sudeste do Brasil (Collembola: Isotomidae). Lundiana 4: 111-116.

MendonçA MC, AbRantes EA (2007) A new species of Isotomiella (Collembola: Isotomiella), with notes on I. bidentata Delamare Deboutteville, 1950 and I. amazonica Oliveira \& Deharveng, 1990. Zootaxa 1652: 41-48.

Mendonça MC, Abrantes EA, Neves ACR (2012) New species of Isotomiella Bagnall, 1939 from Southeast of Brazil (Collembola: Isotomidae). Zookeys 232: 21-30. doi: 10.3897/ zookeys.233.3553

Oliveira E, Deharveng L (1990) Isotomiella (Collembola, Isotomidae) d'Amazonie: les espèces du groupe minor. Bulletin du Muséum national d'Histoire naturelle 12: 75-93.

Submitted: 7 January 2016

Received in revised form: 31 March 2016

Accepted: 18 April 2016

Editorial responsibility: Ricardo Pinto da Rocha

Author Contributions: MCM wrote and illustrated the paper. GCQ took the sample and organized the table.

Competing Interests: The authors have declared that no competing interests exist. 